Ręba Patrycja. Quality management in health care. Journal of Education, Health and Sport. 2021;11(03):11-15. eISSN 23918306. DOI http://dx.doi.org/10.12775/JEHS.2021.11.03.001

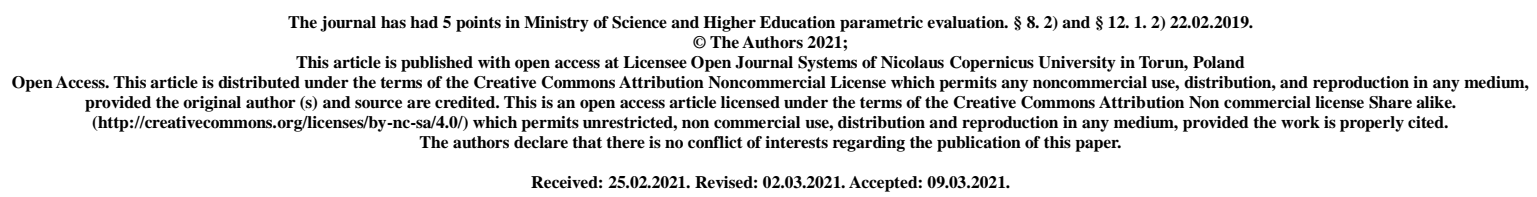

\title{
Quality management in health care
}

\author{
Patrycja Ręba
}

Faculty of Medicine and Health Sciences, Jan Kochanowski University in Kielce

\begin{abstract}
Introduction

Quality in healthcare can be broadly understood depending on your point of view. It is perceived differently by patients who focus their attention on relationships with staff, research and treatment outcomes, as well as the atmosphere and environment in which they are staying. On the other hand, for healthcare professionals, quality is mainly related to the reliable provision of services, in accordance with accepted standards, with the use of specific tools. Quality in health care is a particularly important problem, as it is always associated with the provision of services for the health or even of human life, therefore, for any medical entity, the quality of health services is the most important aspect when providing services. Treatment of the Patient should not only be carried out in accordance with the current knowledge and values important for the Patient himself,
\end{abstract}

Aim

The aim of the work is to analyze quality management in health care.

Material and method

Review of the available literature on the subject.

Results

A satisfactory level of quality of the provided health services can be obtained through thorough and systematic checks of the current level of services and effective actions improving this process. Both internal and external methods of ensuring care are used to ensure a high level of care quality.

Internal methods used by health care facilities include the development of their own quality assurance programs, including examination and assessment of the quality of medical or nursing care, monitoring and prevention of infections and others. 
Patient satisfaction is a common method as patient satisfaction with the care provided is the most important indicator of its effectiveness. Most often, the external quality assessment of healthcare organizations in Poland is subject to compliance with the ISO 9001 standard or with the accreditation standards of the Healthcare Quality Monitoring Center. ISO is the International Standard Organization, which creates various types of standards as well as technical specifications and reports for the entire needs, prepared by a specially appointed Technical Committee 176 (Technical Committee 176 - ISO / TC 176). The ISO 9000 family standards are dedicated to quality management systems and are now used in more than one hundred countries. The implementation of the Quality Management System based on these standards proves the ordering and rationalization of activities (efficiency and effectiveness) and the ability to establish the quality policy.

Conclusions

The guarantee of high-quality service at an appropriately low cost is a significant challenge for health care units that want to survive on the increasingly competitive health market. Patients' expectations are growing, changing, and patient satisfaction research in the field of healthcare becomes the basis for launching the quality improvement process. The medical area is a branch of human activity, where the level of benefits may affect human life and health, so efforts to ensure the highest quality are fully justified, and even advisable.

Key words: management; health care

\section{Article}

Effective provision of medical services requires orderly activities aimed at ensuring the highest quality and safety while minimizing risks and losses. These activities are caused by the enormous importance of the value of human life and the fact that when it comes to saving life and patient safety, you cannot afford to make mistakes, lack of competence and excessive risk. Quality and risk management in health care are more and more often discussed not only in the context of marketing or related to ensuring safety, but also from the point of view of effectiveness and benefits of an effective management system.

The concept of the quality of health services, having developed over the years, has changed its face many times. Until recently, the quality of healthcare was limited only to the simple checking of errors. Over time, attempts were made to predict errors and investigate their causes. Finally, quality became the subject of the overall management of the organization focused on comprehensive quality and risk management. One could say that the concept of quality has recently become a weapon in the competition between medical institutions, but also a hope for patients to be treated in better and safer conditions. There are many definitions that characterize the quality of health services. Starting from a complicated definition as a set of features and properties of a service that determines the service's ability to meet the identified and anticipated needs, through the ability to meet the patient's expectations and needs, and ending with functional and non-functional needs. 
From the point of view of the World Health Organization, quality means services that meet specific criteria and the current state of medical knowledge within the available resources, and provide the patient with maximum health benefit and minimum risk of health loss $[4,5,6,12]$.

The concept of quality in health care is a complex and multidimensional element that is difficult to define unequivocally. It depends to the greatest extent on the point of view from which we will consider it. From the point of view of medical personnel, it will be limited to the proper performance of medical procedures in such a way as to achieve an appropriate health goal. From the patient's point of view, the effect will undoubtedly be important, i.e. the result of treatment and other elements affecting the quality of the services provided, such as the decor of the facility, the medical equipment used, the smooth flow of information between the staff and the patient, or the kindness and empathy of the staff. However, if we consider the concept of quality from the point of view of the payer, i.e. the National Health Fund, it will undoubtedly come to the fore to ensure access to health services in the largest possible area. Considering the dimensions of defining quality in health care, one of the most important is probably quality from the patient's point of view $[7,8,9]$.

The quality and safety of the provided medical services play an extremely important role in modern medicine. Technological progress in recent years, the development of medical knowledge, and new types of drugs allow medical institutions to increasingly meet the expectations of patients. Also for this purpose, more and more often quality management systems are implemented in order to standardize activities, detect errors faster and take effective actions to eliminate their cause and the risk of their occurrence in the future. Management systems, which undoubtedly improve the quality and safety of medical services, as well as ensure greater predictability and stabilization of processes, are increasingly becoming a strategic goal of every medical entity.

Donabedian distinguished three dimensions of the quality of medical services, which together make up the quality of a given service. It is not high quality if at least one of the three categories contains errors or shortcomings. 1. Quality of the structure includes the structure of the organization, the number of employees, their qualifications, equipment, equipment, buildings. 2. Process quality - refers to all activities undertaken or omitted during the diagnosis, treatment, nursing and rehabilitation of the patient. The author emphasizes that the best results are obtained when treatment is carried out in a systematic manner, according to repeatable and verifiable rules. 3. Quality of the result aimed at assessing the degree of improvement in patients' health condition and their satisfaction. It includes indicators such as mortality, morbidity, side effects, etc. [5,12,13].

According to Wasilewski, TQM (Total Quality Management) is "a vision that a company can achieve only through long-term planning, by developing and implementing annual quality plans that will gradually lead it to the implementation of the vision, i.e. to a state in which the following definition of TQM becomes reality. : a corporate culture characterized by an increase in customer satisfaction as a result of continual improvement in which all employees of the company actively participate ". Therefore, TQM is a management philosophy in which all actions taken are pro-quality. 
The components of the company affect the quality of the product and the process of its creation, so all employees work together to form a team that is involved in the company's decision-making processes, at the same time each employee is responsible for their work, and the whole team is constantly striving to improve meeting customer expectations, increasing the credibility and trust of the company. The idea of TQM is to engage employees and take care of the good of the company as a common interest, continuous improvement of qualifications in order to obtain the best results $[1,8,14]$.

In the practice of building quality management systems and their certification, the most important for organizations that are trying to obtain a certificate is the ISO 9001 standard, which contains guidelines for the compliance with which quality management systems are authenticated. The PN-EN ISO 9001: 2009 standard is a system of general requirements that relate to the establishment, documentation, implementation and maintenance of a quality management system and continuous improvement of its effectiveness. The remaining standards are supplementary $[2,8,13]$.

The stages related to the implementation and certification of the quality management system are divided into three stages:

1. Design phase - at this stage, the quality policy is defined, the current state is reviewed and assessed, processes are identified, a schedule of design and implementation works is prepared, lists of procedures are established and quality books are prepared;

2. Implementation phase - this stage includes training, implementation of procedures in units, internal audits and corrective actions as well as organizational changes and finally certification;

3. The maintenance and improvement phase - at this level, external audits, reviews and corrective actions as well as control audits are carried out [9, 11, 15].

The pro-quality goals are implemented through patient orientation and striving to satisfy patients' needs as much as possible, continuous assessment and improvement of the quality of services provided, improvement of internal communication and work organization, rationalization of operating costs, effective management of hospital resources (employee training, equipment and technical base, hospital infrastructure) and continuous improvement of the quality management system based on ISO 9001 standards through systematic control and monitoring of processes, identification of areas for improvement and elimination of visible shortcomings $[1,7,15]$.

Accreditation is one of the external systematic hospital evaluation processes that is carried out in accordance with available standards. Hospital facilities are assessed in terms of a functional whole - the assessment covers the spectrum of clinical activity, management and administration. Accreditation of hospitals in Poland is carried out by the unit of the Ministry of Health - Quality Monitoring Center (CMJ) in Healthcare. In Poland, the first Hospital Accreditation Program was issued in 1998 in Krakow on the basis of patterns from leading accreditation institutions in the world [11, 13, 14].

The program is implemented through the participation of:

- the Accreditation Council - which defines the directions of the accreditation policy, approves the standards and issues decisions and

- Accreditation Center - which is responsible for coordinating and conducting accreditation visits $[2,6,10]$. 
The goals of CMJ focus primarily on supporting activities aimed at ensuring patient safety and improving the quality of medical services, assessing the factors influencing the level of health services and indicators showing the level of service providers' results $[5,7,14]$.

Accreditation for each healthcare facility means accepting new models of attitudes and behaviors as well as patterns of actions taken, it is a practical tool in promoting a new management structure and taking responsibility for the quality and safety of care, and accreditation standards are a powerful tool for managers who shape the care environment and the results of its functioning $[8,9,15]$.

The quality of medical services provided is one of the fundamental problems in the functioning of healthcare. Hard market requirements mean that more and more health care units decide to implement quality management, seeing it as an opportunity to increase their competitiveness and credibility $[6,9,15]$.

\section{Literature:}

1. Wu SH, Lee J. A comparison Study of Nursing Care Quality in Different working Status Nursing Staffs: an example of one Local Hospital. J Nurs Res 2006, 14: 181-188.

2. Grönroos Ch. A Service Quality Model and its Marketing Implications. Eur J Mark 1984, 18 (4): 36-44.

3. Walshe K, Smith J. Healthcare management - quality improvement in healthcare. Wolters Kluwer, Warsaw 2011: 550.

4. Kautsch M. Management in health care. New challenges. Wolters Kluwer, Warsaw 2010: 324325 .

5. Maxwell RJ. Quality assessment in health. Br Med J 1984,288: 1470-147.

6. Wasilewski L. Fundamentals of quality management. WSPiZarz, Warsaw 1998: 28.

7. Hamrol A, Mantura W. Quality management. Theory and practice. PWN, Warsaw 2002: 92.

8. Kautsch M. Management in health care. New challenges. Wolters Kluwer, Warsaw 2010: 324325.

9. Gajewski A. Introduction to quality management. MWSE, Tarnów 2007: 14.

10. Opolski K, Dykowska G, Możdżonek M. Quality management in health services. Theory and practice. CeDeWu, Warsaw 2005.

11. Basics of nursing. A textbook for students and graduates of nursing and midwifery t. 1 Theoretical assumptions. Ślusarska B, Zarzycka D, Zahradniczek K (eds). PZWL, Warsaw 2013: 465-466.

12. Rajewska A. Quality management in hospitals (new trends and challenges). Quality in Healthcare. UJ, Krakow 2011.

13. Lewandowski R. Certified quality. [in:] Management in health care. New challenges. Kautsch M (ed). Wolters Kluwer, Warsaw 2010: 357-359.

14. Kutryba B, Kutaj-Wąsikowska H. Security programs. Zdr Zarz 2003, 6: 18-23.

15. Hauke E. A guide to quality assurance in the hospital. Tips for practical use. Institute of Hospital Organization L. Boltzman in Vienna, Warsaw 1995: 10-11. 